\title{
Teaching Psychologically Challenging Texts with Drama Pedagogy
}

A Prototype Using Ruth Klüger's weiter leben

\section{Lynn Marie Kutch}

\begin{abstract}
Many instructors who treat the subject of the Holocaust have effectively used the vivid imagery of literature and emphasized the personal connection that memoir offers to promote a multifaceted understanding of the intellectually and psychologically challenging material. Applying the kinesthetic techniques of drama in education, as I propose in this article, can greatly enhance the teaching and learning process, and contribute to a more profound awareness of connections between individual experience and national collective histories. When students use drama techniques to become part of a story through, for example, subtext and substitution, they may view themselves not only as more active participants in memory and history, but also as more capable social critics. In this essay, I outline a drama pedagogical model for unlocking Holocaust literature in the foreign language classroom using examples from Ruth Klüger's weiter leben. Although I focus on this one text, instructors can use the series of techniques I discuss here as a prototype for analyzing other psychologically challenging texts in their language classrooms.
\end{abstract}

In his article "The Theater of the Holocaust," psychodramatist and expressive arts therapist Yaacov Naor summarizes the desired outcomes of his drama workshops in which both German and German-Jewish survivors of trauma take part side by side:

Through dramatization and role-playing, the participants can reach a more empathic attitude towards each other and develop appreciation of the differences among them. As a result, they learn to face their own history in a truer, more genuine manner." (Naor 1999: 223f)

Naor's goals for his workshop participants to cultivate a personally authenticated understanding of history and a mutual "empathic attitude" can parallel language educators' aims for students to develop a critical awareness of historic figures, whether victims or perpetrators. Clearly, Naor's work with actual survivors differs from that of language students who engage with literary texts, such as the Holocaust memoir. Analogous to Naor's "use of the body as the major 
medium of expression" (ibid. xx), however, literature instructors can apply similar kinesthetic techniques in order to help language students comprehend target language texts and develop a more profound appreciation of memoir's significance in building national collective histories. Using the example of Ruth Klüger's weiter leben (1992), I would like to detail a series of specific drama pedagogical techniques that support the "easier" task of relating to characters or plot elements on a personal level as well as the higher-level challenge of abstracting that connection to interrogate the "interrelationship of the persecutor-victim roles within each of us and in our society" (Naor 1999: 223). The following techniques can support comprehension by helping students ${ }^{1}$ examine personal connections to characters; yet they also challenge students to question and analyze individual motives within the context of unfathomable historic events.

\section{Outline of Course Goals and Drama Pedagogical Adaptations}

Because of the in-depth analysis that the techniques demand, and the time it takes to perform the multi-layered drama exercises, the methods introduced here work best if students have an entire semester to read weiter leben, which can be supplemented with secondary texts such as Different Voices: Women and the Holocaust (Rittner 1993). The two envisioned overarching course goals correlate to the novel's structure: "eine doppelte Rahmengeschichte," in which "die Sechzigjährige versucht, die Perspektive der Acht- bis Sechzehnjährigen zu rekonstruieren" (Heidelberger-Leonard 1996: 44f). Throughout the reading and the course, students consistently work toward this first level goal of understanding the language and comprehending the smaller episodes located within the larger story. On a higher level of thinking, students recognize how each of the novel's sections contributes to the memoir as a whole; and they develop original research questions that consider the story in historical and literary historical contexts. In order to achieve the former, the instructor can implement methods of character analysis and prop study so that students internalize the plot by infusing it with personal relevance. Exercises in character development also support the two major course goals because students can often identify similarities between the novel's characters and themselves or someone close to them, as well as acknowledge factors that clearly distinguish them by contextualizing the characters' experiences using the supplemental historical readings as a guideline. The techniques work to bridge character development, often based in or linked to personal emotion, to individual motives linked to historical circumstance. In order to promote the second goal of developing and

\footnotetext{
1 The course designation and level of student can vary. Students must be able to read advanced texts (I used weiter leben and additional texts in a 300 level literature and culture course), but as I mention elsewhere in the article, I used the entire semester to read the novel. The techniques described here could also be used in a literature in translation course.
} 
investigating original research questions, students take on the roles of "experts in the field," such as literary critics or therapists, to analyze weiter leben in the context of its critical reception. This sort of role playing, in which students might imagine contributing to an edited volume or collaborating on scripts, emphasizes thinking and writing as an interactive and collaborative process.

\section{The "Unlikely" Pairing of Drama Techniques and Holocaust Study}

Arguably, implementing aspects of character analysis that require students to investigate personal similarities to historical victims and perpetrators may lead to claims of presenting "Holocaust lite," or reducing the event's peculiarity. In terms that point to recent debates about normalizing victims and perpetrators, however, Lomas writes about the benefits of supplementing history instruction with drama: "[Students] have the really challenging task of trying to forget hindsight and to see historical situations_-not as neat and inevitable-but as confused, mysterious, inconsistent and with the participants having mixed emotions and feelings" (2008: 8). When students closely examine the characters of weiter leben and recognize that German and German-Jewish attributes, including "das Gefühl der Nicht-Identität auf deutscher wie auf jüdischer Seite" (Heidelberger-Leonard 1999: 16), do not fit neatly into categories of good victim or bad perpetrator, they become partners in a confused and divisive scholarly discourse. Part of weiter leben's duality stems from Klüger's memoir style, in which the author combines petty everyday conflicts and significant political events. Wolters, writing specifically about Klüger's memoir style, recognizes the advantage that this literary perspective offers students and endorses a thorough examination of one's own personal relationships as a method for grasping the abstract and alien:

Blending the testimony of extraordinary and traumatic events and everyday childhood events, these works position students to learn from their familiar and unfamiliar relationships to the events described. (Wolters 2005: 118$)^{2}$

Similar to Wolters, Zatzman, who has extensive experience using theatre to teach the Holocaust, supports implementing techniques of character development and the arts tocreate opportunities for our students to take ownership of the knowledge they had constructed, to question, and to deepen their engagement with issues about the Holocaust, both historical and contemporary. (Zatzman 2005: 96)

\footnotetext{
${ }^{2}$ Zatzman writes about this method in her article "Staging History: Aesthetics and the Performance of Memory." In preparing for the "Wrapped in Grief" project, Zatzman encouraged students to recognize the "intersection between the domestic and familiar vis-à-vis the extraordinary and incomprehensible" (2005: 97).
} 
As tools to craft answers to questions of identity, dramatic character analysis and academic study of the Holocaust memoir seem oddly similar in stated purpose.

\section{Character Analysis: Identity, Ambiguity, the "Magic If," and Schneewittchen}

In weiter leben, Klüger tells the story of her "Holocaust girlhood," to use the perhaps questionable phrasing from the subtitle of the novel's English translation (Kluger 2003). ${ }^{3}$ She describes her forced expulsion from Vienna as a child, her subsequent internment in Theresienstadt, Auschwitz, and Gross Rosen, and finally her relocation as an adult to New York and California. Throughout the novel, Klüger centralizes the tempestuous relationship that she had with her mother, while at the same time integrating episodes that describe the changing interaction between Jews and members of the dominant community, whether in Austria or Germany. Merging details of a nearly incomprehensible history with the seeming pettiness of mother-daughter quarrels or with "tender moments" involving Austrians or Germans during World War II compounds the novel's emotional complexity for students. According to Heidelberger-Leonard, weiter leben's language has the power "den Leser zu verunsichern, aufzurütteln, zu provozieren" (1996: 45). For example, students often feel secure in the belief that because Jews were treated so poorly, they would treat each other that much more kindly. Involved character analysis of Ruth, her mother, and others in the story challenges that seemingly logical prior belief. Breaking the story into manageable vignettes or scenes with drama pedagogy, however, provides a practical method for mitigating the text's weightiness. When students view the mother within conventional mother-daughter paradigms, or base her expected behavior on their own generally positive maternal images, most of them initially conclude that Ruth's mother was simply cruel. In order to analyze Ruth's mother and her motivations from the inside out, as opposed to students' imposing past personal assumptions of how mothers should be, students employ a character development technique that Robert Barton has termed the "Magic If." Barton articulates the method's importance for refocusing presumptions that often lead to one predetermined conclusion: "You do this, as much as is necessary to stop feeling superior or judgmental, and to play the character from a full heart, in his own vision of reality. You end up feeling that in his place (his total place) you would be bound to act as he did" (Barton 2006: 122). In order to get into a character's "total place," the additional acting technique of "substitution" provides students with a detailed framework of questions and considerations by which they can gain access to characters with both similarities and vastly different political, historical and personal backgrounds.

In her book, The Power of the Actor, Chubbuck details the process of

\footnotetext{
${ }^{3}$ For her English language text, the author uses this spelling. For the original German text, she used the German spelling: Klüger.
} 
substitution, or "endowing the other actors in the scene with characteristics of a person from your real life who best represents the need expressed in your scene objective" (2004: 53). For "scene objective," students identify the character's goal, whether an immediate ambition in the scene or an ultimate aspiration in the entire story. Students often offer the plausible speculation that Ruth, like any other adolescent, desires simultaneous independence and validation from her mother. As for Ruth's counterpart in the relationship, her mother, she may desire a safe world for Ruth, but her powerlessness within this environment materializes in the form of cruelty. Students then have to isolate a counterpart in their own lives who has similar goals or can elicit in the student similar feelings that Ruth's mother can evoke in her daughter. According to Chubbuck, students should not, however, think of the immediately logical replacement, their own mother, as a symbolic alternate for Ruth's mother: "Your SUBSTITUTION is not always going to be a linear or literal path from the character in the script" (ibid. 60). As a method to arrive at the "magic if," students instead catalog and categorize the feelings and struggles that comprise that relationship. This process involves revisiting the character's motivation and obstacles several times and from the perspectives of different characters or real-life people in order to arrive at an appropriate substitution. In the language of acting manuals, obstacles, whether physical, mental or emotional, are the hurdles that make it difficult for the characters to achieve their goals, whether they endeavor to have the perfect relationship, to get others to accept them, or simply to survive. As the students learn from the course's accompanying secondary readings, the conditions of the Holocaust raised these obstacles to an extreme level, leaving the characters with virtually no control over their physical and mental barriers. Focusing on relationships over which they have or had little control can help students use substitution as a "tool for emotional history," in Chubbuck's words (ibid. 53). Through the many episodes that describe her mother, Klüger provides documentation for this emotional history that students must then interpret within the framework of one of their own difficult relationships, perhaps an abusive partner or an overly demanding friend.

Students can also isolate elements of an emotional, personal history by viewing "still frames" as dynamic and independent yet integral parts of the novel. This technique mirrors similar "tools associated with the conventions for dramatic action [that] have the function of holding time still for a moment so that we can visualize and investigate human beings and their actions in more detail" (Abbott). As part of the process of "holding time still," or viewing a segment of history, students can learn from the supplemental texts about the historical background in Vienna when regulations prohibited Jews from being out in public without wearing their stars. Departing from historical fact, students analyze in-depth an episode in which Ruth defies her mother and goes to see Walt Disney's 1937 movie Snow White (Schneewittchen), which had opened in Vienna in 1938. With a decision that may defy logic for students who have read about political and social conditions in Vienna at the time, Ruth's mother, 
seemingly fully aware of the potential consequences, does not stop her daughter from going to the movie. By applying techniques of character development, and particularly substitution, students can begin to postulate that the conflict far supersedes a mother-child disagreement. An additional method for devising substitutions and replicating or at least approximating the characters' feelings is one in which actors mimic the postures of figures in artwork, photography or sculpture. Because this particular episode actually focuses on a film and its significance in Ruth's childhood, the instructor can mix media sources and have students mimic the postures of the figures in one significant cel ${ }^{4}$ from the movie: the scene in which the wicked stepmother extends the poisoned apple to Snow White. Howey, in his acting manual The Actor's Menu, describes the kinesthetic technique of physically restaging the action or mimicking the characters in his section "Getting the Impression." Although Howey suggests photography as the medium to imitate, the instructions for the actors remain the same: "assume the exact pose of the person in the photograph [...]. Create the feeling or attitude you get from the photo. Hold the pose and let any ideas and feelings come forth (Howey 2005: 161). Even has expanded on this idea in a more recent publication with her development of Empathy Questions; and she also touts the value of such an activity for developing feelings, and therefore identifying a person for substitution: "Imitating the sitting posture helps learners get a bodily-kinesthetic impression of the statue, and the empathy questions are designed to encourage them to develop their own thoughts and ideas shaped by the position they have adopted" (Even 2008: 165). This method of physical mimicry helps students become emotionally closer to the figures, as the following section may help verify.

In the above-mentioned scene from Snow White, the stepmother hovers slightly above Snow White with the apple while Snow White bows down in front of the stepmother and reaches for the piece of fruit. When the students physically take on these positions, they immediately develop a physical sense of the abstract concepts of superiority and subservience. The student assuming Snow White's pose gets the distinct impression that the other character is looking down on her, whether figuratively or literally. While this could superficially describe Ruth's relationship to her mother, probing the dynamic further with Chubbuck's substitution questions leads students to the more nuanced interpretation mentioned earlier that the word "cruel" alone does not fully describe Ruth's mother. Snow White, in a physical posture that indicates obeisance to an outwardly evil character, seems poised to answer Chubbuck's questions for establishing obstacles and motivation: "what do I need? Who's unlikely to give it to me?" or "who would it be emotionally painful to need anything from?" (Chubbuck 2004: 65, 67). Sometimes the seemingly least likely parallel helps the student analyze the character more effectively because

\footnotetext{
${ }^{4}$ In animation jargon, a cel is short for celluloid, and signifies the transparent sheets used along with paper in traditional hand-drawn animation. See Taylor $(2004,22)$ for a technical description of the process. Because animators have to work on each cel separately, they appear as still frames, which is what I analyze here.
} 
of the apparent incompatibility. For this substitution, for example, a student might cite a boss/ employee relationship. In response to "what do I need," the student might say that he needs more freedom or latitude in the work environment, but his boss is unlikely to grant him that autonomy because the student displays immaturity, or has not for some reason earned an appropriate level of respect from his boss. During the process of "tough love" that the boss implements, the student either acquires a set of valuable job skills, or the boss's imposed limitations will impede learning and personal development. In the case of Ruth and her mother, students can either understand the motivations of her mother because of the parallel with their story, or they never forgive the character, as Ruth does not ever fully exonerate her mother for her behavior. Understanding that the novel's relationships are as multi-faceted as real-life relationships, students can more readily justify or judge the mother's behavior when she takes on the contours of a person in their own lives. After applying substitution techniques that bring personal relationships and human motivations into clearer focus, students who initially may have condemned the mother's lack of regard for Ruth move closer to detecting valid, if not entirely excusable, reasons for the mother's behavior.

For the final step in the character analysis, students complete a writing assignment inspired by two of Howey's characterization techniques: "Subtext" and "Reinventing The Character's Story In One Expressly Worded Paragraph." (164-166). In this extended phase, students work toward the goal of producing a more acute character study that also incorporates the ancillary historical course material. In order to advance beyond the mother's overtly malicious statements, the students must understand the concept of "subtext," or the "the thought and feeling beneath the text:" "It's what the character actually thinks, as opposed to what the character says" (Howey 2005: 135). Not only does the process of substitution allow students to visualize a more complex person than the one-dimensional somewhat abusive figure that emerges from Ruth's descriptions, but the additional study of historical factors that may have influenced the mother equips students to delve more deeply into the mother's character. For example, when Ruth's mother, fully aware of the danger that Ruth could encounter, told her to go to the movie anyway, her subtext may have expressed: "I am sending her because I want her to live in a world where a child can do the things a child should do." After students compile elements of a subtext, they progress to the expressly worded paragraph, which Howey presents as a sort of fill in the blank exercise in which an "actor brings a character to life with his or her own point of view" (ibid. 164). Howey provides detailed instructions for constructing the paragraph: "the words in bold are actable, underlined words are inner life, prior experience in parentheses, and IM indicates inner monologue" (ibid. 165). Producing this pre-writing exercise following Howey's formula, students may feel a better sense of preparedness when responding to a discussion topic that requires them, for example, to describe the mother's character from her own perspective, that is Ruth's mother tells in the first person why she makes the choices she does, or explains her 
supreme lack of choice. For the first essay topic, students consult supplementary historical readings about mothers and other women who had to make very difficult decisions. Whether students choose to defend or chastise the mother in this first essay assignment, their carefully planned writing reveals the nature of the subtext that they have uncovered about the character.

The expressly worded paragraph should ideally take on a compact yet dense and complex form, aesthetically similar to that of the fixed still frame that inspired this phase of analysis. Taking substitution together with Naor's psychodramatic techniques, by which students "enact his/her experiences, dreams and feelings [and] discover the deep meaning of his/her own history of experiences and their influence upon his/her decisions and acts in life," students augment the mother's role with their own experiences (Naor 1999: 223). The nearly universal combination of power, resolution and fear inspires a character description that may include the question "how will you behave in the face of risk?" (Chubbuck 2004: 54). Pondering some of Chubbuck's organizing categories, such as "unresolved issues you think you've resolved," or "people you think no longer hold any power over you but still prevail in your heart" (ibid. 76), students identify the biggest risk they think they took, their greatest example of loss, and what or who wields power over them. A possible result based on Howey's formula of the expressly worded paragraph follows:

Ruth's mother, an outwardly domineering woman and mother is fearful that she will lose her daughter just as (she has her son). Though she cares about Ruth, she masks it by keeping a distance to her. She believes that Ruth holds her in disdain, but she would rather be distant than get too close to someone she loves whom she thinks she could lose.

Because actual performance is not a component of the course, students can transform the performative impulse of character development onto an original visual art rendering. Students essentially transform the words of their character descriptions into the visual impression of a still frame sketch, that could be even further analyzed using the same techniques detailed above. Physically taking on the position and demeanor of the figure in their drawn sketch enables students either to validate or reverse their initial reactions in a very personal way. The process of substitution, or identifying personal connections from their own complicated lives, often prevents students from viewing a character too narrowly or categorizing them as one singular type. For example, if the students had one fixed interpretation of the mother from the reading, the physical positioning can call their initial understanding into question, even allowing a more empathic mother figure to emerge.

\section{4 "Close Readings" of Symbols as Theatrical Props I: Objects of Jewish Identity}

Another effective drama pedagogical method to explore the text and scrutinize its characters involves detecting and analyzing literary symbols and researching 
them as props, or as tangible extensions of the character's identity or memory. weiter leben, which moves through geographical settings and chronological phases of Ruth's development, offers a range of props to manipulate. Because some objects, such as the Star of David and the tattoo, directly correlate to the Jewish experience, a close reading of them can provide students with a solid foundation of that history as well as individual reactions to historical events. By supplementing their analyses of the objects with Ruth's contradictory statements from the text concerning the items, however, students can progress past their initial assessments to discover the object's subtext. When asking actors to discover the nature of a prop, especially an unfamiliar object, directors often instruct performers to form a close bond with the object. While it may seem nearly impossible or even perverse for non-Jewish, American college students to establish an emotional bond with the star, an outward symbol of oppression for one specific group, acclaimed acting teacher Stella Adler's statement that "there are no props just personal belongings" (Rotté 2000: 78) can narrow the focus on the star from historical object to a part of personal identity and a foil for individual feeling. After a preliminary exercise of listing general associations to the star such as humiliation or oppression, students consider the object in the context of Ruth's reaction to the star, as cited in the novel: "Ich kann nicht sagen, dass ich ihn ungern getragen habe, den Judenstern. Unter den Umständen schien er angebracht. Wenn schon, denn schon" (Klüger 1992: 50). Given this blatant contradiction to what students may have learned about the humiliating nature of the star, they reassess the star's significance by discovering its subtext for Klüger. If at first they imagine a deeply ashamed character wearing the star, Klüger's seemingly impudent statement of pride or acceptance undoes the perception. At this point, students may not be able to relate fully to a government-imposed symbol, but they should be able to identify an object of substitution from their own lives that awakens ambiguous or troubling feelings. As with the seemingly disparate substitution of a boss/employee relationship for the mother/daughter relationship, students could, for example, replace the star with an article of clothing that they had to wear, or the lack of a certain article of designer clothing, that painfully set them apart from everyone else. When they think back on their experience, they can try to remember whether they embraced being different or whether it figuratively "scarred them for life," to use a common exaggeration when recalling past experiences. As with the boss/employee example cited above, even if the outcome does not directly mirror Ruth's situation or attitude, the inconsistency leads the students to make important comparisons and contrasts between the historical significance of a "Holocaust girlhood" and an American childhood.

The second item mentioned above, the tattoo, intensifies the notion of a prop as an extension of a character because of its physical inseparability, permanence, and its historical connotation. In her instruction on the use of props, Adler does not advocate "confining a prop to some banal lifelessness, but giving it an imagined personality - a theatrical reality logical to the prop's nature" (Rotté 2000: 78). Precisely because it seems so profane to apply procedures of a 
prop study, which might usually consider banal items such as a walking stick or table, to a concentration camp tattoo that signifies disregard for individual life, the symbol actually gains critical vibrancy. If students previously thought of the tattoos as superficial markings on inmates of concentration camps, a prop study whereby students could strengthen their personal connections and interpretations reemphasizes that weiter leben tells the story of complex individuals and not a homogenous collective. The prop study becomes more complicated but also more productive when students try to reconcile their initial understanding and judgment of the tattooed numbers with Klüger's seemingly carefree statement from the novel: "Mit dieser Tätowierung stellte sich bei mir eine neue Wachheit ein, nämlich so: Das Außerordentliche, ja Ungeheuerliche meiner Situation kam mir so heftig ins Bewusstsein, daß ich eine Art Freude empfand" (Klüger 1992: 116). In speaking about her "Wrapped in Grief" project Zatzman describes a process made more difficult precisely because of these ambiguities and challenges to previously held beliefs: "The complexity of this undertaking lies in the recognition that we are working between spaces of documentation and the (im)possibility of knowing" (Zatzman 2005: 100). Because of the improbability, or impossibility, of students directly relating to this type of tattoo, they must first identify a parallel object and then complete a character comparison between themselves and Ruth to arrive at, in Zatzman's words "the intersection between the domestic and familiar vis-à-vis the extraordinary and incomprehensible" (ibib. 97). If a student decides that his own tattoo, now permanent, recalls an unpleasant temporary phase in his life, he relates on one level, but also understands the vast differences. Trying to understand how Ruth manages to feel a sense of joy with her object provides a constructive starting point for critically linking the familiar and the exceptional.

\section{A "Close Reading" of a Symbol as Theatrical Prop II: An Object of Jewish and Dominant Culture Relations}

Identifying an object or symbol with proportionate insignificance as compared with the star or the tattoo is also an effective analytical tool. In a relatively short episode, Ruth receives an orange from an Austrian man while they both ride public transportation in Vienna. As testament to its seeming triviality, if actors were to perform this scene, it would take a matter of seconds. Nonetheless, this potentially unnoticed scene can familiarize students with subtle acts of kindness practiced by dominant communities, the study of which has contributed to contemporary critical dialogues that consider "ordinary" or "good" Germans during World War II and the Holocaust. ${ }^{5}$ This concept of Germans, or in Klüger's case, members of the dominant Austrian community, as "good" or

\footnotetext{
${ }^{5}$ Within the past few years, the trendy if perhaps indistinct concept of "The Good German" has evolved into a controversial device for the cultural representation of an outwardly virtuous but morally ambiguous figure. Challenging the long-held assumption of the German as perpetrator, the Good German emerges from a narrative of specifically chosen historical events that corroborate his heroism or even victimization.
} 
"non-perpetrators" presents a new line of thinking for American students who primarily learn military or public history and therefore rapidly and generally classify victims and perpetrators. In this short episode, an Austrian stranger presses an orange into Ruth's hand as their streetcar enters a tunnel. The central act of gift giving may evoke many questions from the students, such as why the man would do this, or why he would take this great risk given the political circumstances. Using some of the same methods that they would for analyzing literary symbols, students first create an index of general associations with an orange that will help them create the object's subtext. After offering symbolic counterparts like "life" and "health," students can expand on the descriptors to explain the significance of this scene for the memoir as a whole, or where this scene and object fit into the larger historical picture. Just as an actor has to decide exactly how to use, incorporate and reveal the prop and its significance to the audience, the students perform a close reading of the prop by first deciding how they would physically manipulate the orange in order to show, rather than tell about, its potential meaning. With some guiding questions from the instructor that show students how to work with the orange, they can progress from viewing it merely as a piece of fruit in the printed episode to understanding the orange as an object that articulates something about Jewish experience within the dominant culture. By transcending the printed word and treating the orange as an extension of the character's body, students can understand the real life and real world significance that literature and symbols carry. Additionally, they begin to think critically about the relationship between an ostensibly banal object and its potential historical significance.

In the first step, students work very closely with the orange as tangible object, and are directed through a series of questions whose answers can endow the orange with personal meaning. Each question in the series raises the object's level of significance: after asking the very simple question "how do you hold an orange?" the instructor can ask "how would you hold this object if it were a very valuable gift from someone close to you?" The students then react to the question "how would you conceal the orange if you didn't want anyone else to see it?" Because the object seems so ordinary to the students, their attention is drawn to its subtext, such as what possible reasons there would be for concealing an orange. Just as an actor would perform additional research to understand his character's actions and motivations fully, students can integrate details from primary and secondary readings in their research and written prop analysis. They may get a sense of the scarcity of this form of produce and therefore its status as a valuable commodity; or they could metaphorically extend the idea of scarcity and preciousness to denote the gradual loss of decent human relationships. Concentrating on subtext, students then try to decide what the man wants to convey with the orange. In the section of his acting guide, "Masking and Physicality," Howey explains how "masking can also be carried out with physical actions. For example, a bartender rearranges bottles, masking the fact that he doesn't want to hear the customer tell another bad joke" (Howey 2005: 145). Although the trivial example of a bartender initially does 
not seem to correspond to this historically heavy scene, the contrast of action can inform the next phase of the activity in which they have to comprehend an emotionally dense situation while handling a commonplace object. As a last phase of the activity, students once again manipulate the prop, but this time they have to pass it to another student while uttering a phrase that represents the man's motivation. Students might suggest that he gives her the orange to say that he wishes things were different, that not all non-Jews are enemies or brutal, or that he emphasizes through this small gesture his reduced amount of autonomy under these political circumstances.

The orange also plays a role in a subsequent scene when Ruth shows her mother this unexpected gift from a stranger. As could be anticipated from the prior character analyses, her mother interprets the gesture as an insult: "Was fällt dir ein, Geschenke von Fremden auf der Straßenbahn anzunehmen? Wir sind keine Bettler" (Klüger 1992: 52). Because this second interpretation of the orange has to do with the mother-daughter relationship, it is helpful for students once again to apply the methods of substitution. Culhane's method of working with objects as described in her article "Memory, Memoir, and Memorabilia: A Generative Exercise" (2004) provides a productive framework for working with objects that may trigger past memories. For the first part of the exercise, Culhane asks her students to bring something of material importance to class, whether "written memorabilia" such as diaries, books, letters, or "visual memorabilia," such as photos or illustrations, or "personal memorabilia," such as clothing, glasses, jewelry, or footwear. Culhane's questions urge students to strengthen their personal understanding of this object, and therefore endow it with emotions that will help them with a more reflective interpretation of the orange. First, students recall how they acquired the object and why it is now important to them. Then, as a way to bestow certain attributes upon the object, students imagine and describe the consequences of losing that object (cf. ibid. 312). For example, if they were to lose the only photograph they have of a deceased relative, they would no longer have a tangible artifact from that person's life. This could create difficulties for them in remembering that person as vividly as they might with the photograph close at hand. If they imagine losing an article of clothing or accessory, they may describe a diminished sense of security that the object had afforded them. In order to understand the scene between Ruth and her mother, students could possibly think of an article of clothing of which their parents did not approve, or that even caused arguments. When they try to discover the subtext of their parents' objections to the item, even if it is an object given as a kind gesture, then they can begin to perform the substitution of their orange and their chosen object. Students can explain in interviews or conversation with other students why their chosen object is so important to them. This proves especially effective when the other students cannot at first understand why a pen or stuffed animal might be so precious to a fellow classmate, until they realize its emblematic value as a reflection of personal memory; and extending that idea to the novel's analysis, that memory's place is collective history and how that history is now remembered. 


\section{Conclusion}

As part of her subtle criticism of current museum culture, Klüger writes in weiter leben "es ist unsinnig, die Lager räumlich so darstellen zu wollen, wie sie damals waren. Aber fast so unsinnig ist es, sie mit Worten beschreiben zu wollen, als liege nichts zwischen uns und der Zeit, als es sie noch gab" (1992: 78). If the study of objective facts, measurable statistics, or even the words on the page of a novel, mirrors the temptation to visit preserved camp museums in order to understand what had happened there, then perhaps the "private" historical study of individuals and their sometimes universal motivations "liegt dazwischen." I have argued in this article that instructors and students can construct this emotional bridge between time frames and frames of mind with carefully designed, directed, and diligently followed methods of drama pedagogy. Vass, in his article "Drama and History: A Theory for Learning" (2008) echoes the philosophy of incorporating drama to promote an organic way of learning history in terms that are relevant to studying a memoir and discovering what "lies between" dates in history and present day study of them:

Clearly it is not possible to think someone else's feelings, but what [students] can do is project their own ideas into the character. In this way, their "personal luggage" - opinion, ideas, experiences and prejudices-can be aired, examined and discussed and from this a clearer understanding of history can emerge. (2008: 14).

By applying and modifying a variety of drama-in-education techniques, students can supplement their largely objective previous knowledge with personally validated insight. Using that enhanced sense of awareness, students can attempt to reconcile and critically analyze the intertwined areas of German history, personal relationships, and the psychology of the victim. In his article, "Reflections on How the Theatre Teaches," Levy (2005) explains in general terms how theater, and I would argue analogous drama pedagogical techniques, can educate the emotions: "the theatre teaches by focusing and intensifying our emotions and thereby heightening an audience's experience of feeling [...] the theatre can teach by isolating the emotions and examining them separately (ibid 24). Examining and isolating their own emotions and becoming part of the story themselves through subtext and substitution gives students the opportunity to, as Zatzman emphasizes, "writ[e] themselves into personal and public memory" (2005: 97). The kinesthetic techniques of drama that I outline here can not only enhance the teaching and learning process, but can also contribute to a more profound awareness of connections between individual experience and national collective histories. If words seem inadequate to encapsulate Holocaust experiences, as Klüger maintains, then drama pedagogy can bring readers closer to communicating the spirit of life found in language, with all its conflicts and motivations. 


\section{Bibliography}

Klüger, Ruth (1992): weiter leben: Eine Jugend. Göttingen: Wallstein Verlag.

Abbott, Luke. Dramatic Conventions-Their Use and Abuse-An Attempt at An Explanation. Papers on Drama and Mantle of the Expert.

http://www. mantleoftheexpert.com/about-moe/articles/, accessed June 14, 2009.

Barton, Robert (2006): Acting Onstage and Off. Belmont, CA: Wadsworth.

Bolton, Gavin (1985): Changes in Thinking about Drama in Education. In: Theory into Practice 24/3, 151-57.

Chubbuck, Ivana (2004): The Power of the Actor: The Chubbuck Technique. New York: Gotham Books.

Culhane, Alys (2004): Memory, Memoir, and Memorabilia: A Generative Exercise. In: Pedagogy 4/2, 310-312

Even, Susanne (2008): Moving in(to) Imaginary Worlds: Drama Pedagogy for Foreign Language Teaching and Learning. In: Unterrichtspraxis/Teaching German 41/2, 161-170.

Heidelberger-Leonard, Irene (1996): Oldenbourg Interpretationen weiter leben. Eine Jugend. München: Oldenbourg Verlag GmbH.

Howey, Bill (2005): The Actor's Menu: A Character Preparation Handbook. Lakewood, CO: Compass Publishing.

Kluger, Ruth (2003): Still Alive: A Holocaust Girlhood Remembered. New York: The Feminist Press.

Levy, Jonathan (2005): Reflections on How Theater Teaches. In: The Journal of Aesthetic Education. 39/4, 20-30

Lomas, Tim (2008): History Coordinators' Dilemmas: Drama, Creativity, Literature and the Curriculum. In: Primary History: The Primary Education Journal of the Historical Association 48, 8-9.

Naor, Yaacov (1999): The Theater of the Holocaust. In: Levine, Stephen K.\& Ellen G. Levine (eds.): Foundations of Expressive Arts Therapy. London: Jessica Kingsley Publishers, 223-239.

Rittner, Carol Ann \& John K. Roth (eds.) (1993): Different Voices: Women and the Holocaust. St. Paul, MN: Paragon House Publishers.

Rotté, Joanna (2000): Acting with Adler. New York: Limelight.

Taylor, Richard (2004): Encyclopedia of Animation Techniques. New York: Book Sales, Inc.

Vass, Peter (2008): Drama and History A Theory for Learning. In: Primary History The Primary Education Journal of the Historical Association 48, 13-14.

Wolters, Wendy E. (2005): A Bridge Between My Memories and Yours. In: Transformations 16/2, 118-26. 
Zatzman, Belarie (2005): Staging History: Aesthetics and the Performance of Memory.

In: The Journal of Aesthetic Education 39/4, 95-103.

Primary Source -

Secondary Sources - 